\title{
La intimidad del cronista como materia de estudio del propio cronista. Un estudio de caso: Gabriela Wiener
}

The privacy of the journalist as a field of study of the journalist himself. A case of study: Gabriela Wiener

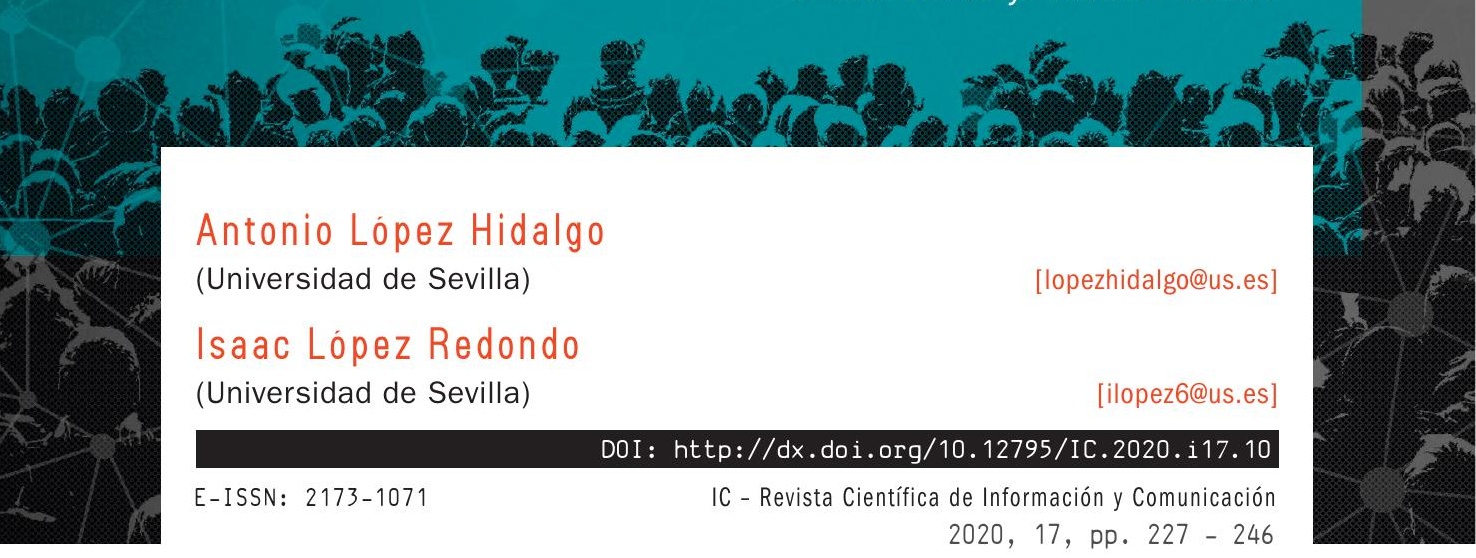

\section{Resumen}

La periodista peruana Gabriela Wiener es una de las más interesantes precursoras de la crónica personal en el continente americano, al mismo tiempo que es la profesional que mejor ha sabido ejercer y entender el periodismo gonzo. Su intimidad es la materia de estudio de la cronista. Porque también describirnos es describir el mundo, señala Wiener. Para alcanzar los objetivos planteados, hemos utilizado como método de investigación el análisis de contenido, así como el estudio de caso en profundidad de la obra periodística de Gabriela Wiener.

\section{Abstract}

Gabriela Wiener, Peruvian journalist, is one of the most relevant heralds of the personal crónica of the American continent, but she is also the journalist that better applied and understood the gonzo journalism. In this paper we will analyze how Wiener's personal crónicas are not just a narration in first person where the author is present at all times. The subject of study of the reporter is intimacy, because describing ourselves is just like describing the world, as Wiener states. In order to reach the objectives laid out in this research, we analyze the content and we study in depth the journalistic works of Gabriela Wiener. 
Palabras clave

Crónica personal, periodismo gonzo, periodismo de inmersión, intimidad, sexo

\section{Keywords}

Crónica, journalism, gonzo, gonzo journalism, intimacy, sex

\section{Sumario}

1. Introducción. La crónica personal de Gabriela Wiener

2. Metodología de la investigación. Objetivos

3. El periodismo gonzo y Hunter S. Thompson

4. La presencialidad de Gabriela Wiener en sus textos

5. De Nueve a lunas a Llamada perdida

6. Dicen de mí: un libro en el que los otros hablan de Gabriela Wiener

7. Conclusiones y discusión

8. Fuentes documentales

\section{Summary}

1. Introduction. Gabriela Wiener's personal chronicle

2. Research methodology. Goals

3. Gonzo journalism and Hunter S. Thompson

4. The presence of Gabriela Wiener in her texts

5. From Nueve a lunas to Llamada perdida

6. Dicen de mí: a book in which others talk about Gabriela Wiener

7. Conclusions and discussion

8. Documentary sources 


\section{Introducción. La crónica personal de Gabriela Wiener}

Nacida en Lima (Perú), Gabriela Wiener es escritora, poeta y periodista. Vive afincada en España desde 2003, antes en Barcelona y ahora en Madrid. Forma parte del grupo de nuevos cronistas latinoamericanos y es una de las más interesantes precursoras de la crónica personal en el continente americano. Pero, sobre todo, Wiener es la profesional que mejor ha sabido ejercer y entender el periodismo gonzo. Basta con leer el título de uno de sus artículos: “Gonzo soy yo" (Wiener, 2011c). Estudió Lingüística y Literatura en la Universidad Católica de Lima, y un máster en Cultura histórica y Comunicaciones en Barcelona. Sus primeras crónicas vieron la luz en la revista Etiqueta Negra, y fue redactora de la sección cultural y del suplemento dominical del diario El Comercio de Perú. Ha escrito en medios como Soho, Paula, Etiqueta Negra, Caretas, Travesías o Virginia Quaterley Review. En España ha trabajado como redactora en la revista Lateral y ha publicado en La Vanguardia, El País Semanal, El Periódico de Cataluña, Letras Libres, Primera línea y Quimera. Es autora de la plaqueta de poesía Cosas que deja la gente cuando se va y ha publicado además tres libros de crónicas: Sexografías, entre el periodismo narrativo y las memorias sexuales; Nueve lunas, una crónica-ensayo sobre su embarazo, y Llamada perdida, un libro que, según Jorge Carrión, quien escribe en la contracubierta que no se parece a ningún otro, "un libro autobiográfico, político, sincero y radical donde se habla de tríos sexuales, de amigos lejanos, de literatura, de supersticiones numéricas, de una hija y un marido, de España y de Perú".

Su compromiso con la profesión periodística la ha llevado a practicar el periodismo de inmersión, así como el periodismo encubierto y el periodismo gonzo. De esta manera, se ha infiltrado en cárceles limeñas, se ha expuesto a intercambios sexuales en clubs de swingers, ha convivido con travestis y putas en el Bois de Boulogne parisino, se ha sometido a un proceso de donación de óvulos, ha participado en un ritual de ingestión de ayahasca en la selva amazónica y se ha colado en alcobas de superestrellas del porno como Nacho Vidal.

Gabriela Wiener es la principal representante del periodismo gonzo en Latinoamérica. Aunque, en lo personal, prefiere a los periodistas que, "en lugar de encubiertos, van y se arriesgan con su DNI, pero no siempre se puede". Wiener categoriza, sin dramatizar, los tipos de periodistas que practican la inmersión y que ella percibe: infiltrados, exhibicionistas, inmersos, empáticos, testimoniales, vivenciales, gonzos, suicidas, y todos son con sus matices "la pesadilla de los defensores de la objetividad en Periodismo". Y, al 
respecto, recuerda una frase de Günter Wallraff: "Son más peligrosos los que tratan de vender que son objetivos sin aclarar quién les paga o los favores que deben”. En este sentido, Wiener diferencia claramente dos tipos de periodistas gonzo (Wiener, 2011c).

En primer lugar, el periodista que escribe lo que le da la gana desde muy lejos, de lo que no tiene ni idea, aunque sabe que su destino está en ese mismo lugar "donde las certezas se le acaban". En este grupo incluye al estadounidense Ted Conover, "activo participante de los mundos ajenos que frecuenta". Mezclando la antropología y la literatura, se infiltra durante un año como guardia en una prisión de Nueva York, experiencia de la que escribe un libro "interesantísimo" editado en 2002 por Alba Editorial, Novato, guardia en Sin Sting, y cruza hasta tres veces la frontera junto a inmigrantes mexicanos. En este mismo grupo de gonzos, pero "al lado de los periodistas no empáticos sino "hepáticos'”, incluye al alemán Wallraff, "un periodista de los indeseables, o sea, de los necesarios", que, cada vez que se ha involucrado en una de sus performances periodísticas, ha logrado que se hable de temas de los que nadie hablaba, pero que nunca pasan de moda, como la discriminación racial, los abusos de las multinacionales o "la guarrería de la prensa amarilla". La periodista peruana recuerda que la revista colombiana Soho es uno de los pocos lugares donde se puede practicar algo parecido al periodismo gonzo y "reportear en primerísima persona universos insospechados". Cita a colaboradores de esta publicación como Efraín Medina Reyes, que contó su vida como boxeador o su operación de cirugía estética de cara, o Andrés Felipe Solano y su crónica sobre cómo vivió seis meses con el salario mínimo (Wiener, 2011c).

Y en un segundo grupo sitúa a aquellos periodistas que escriben acerca de lo que más conocen o creen conocer. En este bloque incluye una parte de la obra de Gay Talese. En Retratos y encuentros, explica cómo surgió su primer reportaje: se le perdió su perro. En su nota autobiográfica, el joven Talese llega hasta el cementerio de perros sobre el que realiza una exhaustiva investigación, con datos precisos y "párrafos extremadamente bien escritos". En el origen de todo, escribe Wiener, está un perro perdido. 0 una sastrería, el negocio de su padre y de su tío, "donde confeccionaban trajes para temibles capos de la mafia italiana del sur”. Éste será el punto de partida de su libro Honrarás a tu padre, la historia verídica del clan más poderoso de la mafia italiana en América, que "alterna con la génesis de su propia familia, para retratar más que la criminalidad, la intimidad de unos gangsters". Entre otros, cita también al chileno Pedro Memebel y su voz travestida, narrando los vericuetos de la identidad de género en Latinoamérica y "su marginalidad lírica y canalla"; al argentino Alan Pauls, cuando escribe sobre sus talleres de masculinidad; a la mexicana Alma Guillermoprieto que, en en su libro La Habana en el 
espejo, mezcla sus memorias como joven profesora de danza con la crónica desencantada de la revolución cubana y su reflexión sobre el arte en ese entorno; 0 a Jorge Carrión, por sus crónicas transfronterizas, como Australia, en las que hay "una obsesiva búsqueda en sus raíces familiares", o en Crónica de Viaje, el libro preferido de Wiener, en el que incluye un autorretrato de su pene (Wiener, 2011c).

Inmerso, encubierto o gonzo, escribe Wiener, "aunque el periodista permanezca oculto tras su libreta, cuando narramos, nos narramos". Para ella todos estos periodistas que ha mencionado y tantos otros más son "gente que piensa, recuerda y siente, se rasca y eructa, mientras investiga y persigue la dichosa verdad". Y concluye: "El periodista que actúa, que se involucra, que entra en otros mundos, nunca vuelve a salir igual. Todo cronista de sí mismo es un cronista de la realidad. Pero también, cada acto de escritura, incluso si ésta es periodismo, es en última instancia la historia de la mirada de su autor. Hasta este artículo es un artículo sobre mí" (Wiener, 2011c).

\section{Metodología de la investigación. Objetivos}

El presente trabajo de investigación se plantea como principal objetivo analizar la obra periodística de Gabriela Wiener, considerada la principal precursora del periodismo gonzo en español. Dicha modalidad del periodismo de inmersión, caracterizada por la participación directa del periodista en los hechos que después narrará, presta especial atención a esta experiencia personal del reportero, que imprimirá en el relato todas las impresiones y sensaciones vividas en el transcurso de un determinado acontecimiento. Tal ves el máximo exponente de esta forma de escritura sea el norteamericano Hunter S. Thompson, quien planteó por vez primera el término gonzo en su crónica "El derby de Kencky es decadente y depravado". Pero al autor de Miedo y asco en Las Vegas le precedieron autores como Nelly Bly o George Orwell en esta particular manera de narrar la realidad donde la subjetividad cobra una relevancia especial.

Las líneas que nos ocupan pretenden situar la obra de Gabriela Wiener en el contexto del ejercicio del periodismo de inmersión a nivel mundial, comparándola con la de otras figuras relevantes de esta modalidad periodística. Para ello hemos recurrido al análisis de contenido como principal herramienta metodológica. De acuerdo con Fernando López Noguero (2002: 173), en tanto que esfuerzo de interpretación, el análisis de contenido se mueve entre dos polos: el del rigor de la objetividad y el de la fecundidad de la subjetividad. En este sentido, este instrumento metodológico "disculpa y acredita en 
el investigador esa atracción por lo oculto, lo latente, lo no aparente, lo potencial inédito, lo 'no dicho', encerrado en todo mensaje”. El presente trabajo supone, pues, un análisis de contenido de la obra de la periodista peruana, centrado especialmente en tres libros: Sexografías, Nueve lunas y Llamada perdida.

Por otra parte, el plan de investigación se materializa también en un estudio de caso en profundidad. Este técnica se lleva a cabo "mediante el acopio y asimilación del material bibliográfico disponible sobre el objeto de la investigación", como recuerda Roberto de Miguel (2005: 288-289). Para ello, como decimos, se realiza un breve recorrido por la obra de Hunter S. Thompson que sirve como punto de partida para analizar las aportaciones de Gabriela Wiener al periodismo de inmersión, focalizando la atención en los tres libros señalados, con objeto de desvelar sus procedimientos de trabajo, los temas por los que se interesa, el tono de su prosa y aquellas características que la acercan, pero también la separan, de otros referentes del periodismo de inmersión, una corriente que se enmarca a su vez dentro del periodismo narrativo, que ha cobrado una especial revelancia en América en las dos últimas décadas.

\section{El periodismo gonzo y Hunter S. Thompson}

El periodismo gonzo constituye una modalidad de periodismo de inmersión en la que se prioriza el protagonismo del periodista, cuya participación en los hechos investigados puede condicionar y alterar el curso de los acontecimientos. Para José Luis Dader (2007, p. 37), representa, de hecho, "la reivindicación máxima de la subjetividad del reportero" y "la versión más radical del nuevo periodismo". Se trata de un modelo de narración en el que el reportero intenta transmitir una experiencia en la que ha participado de forma directa, con especial atención a sus impresiones sobre los hechos, fruto de la observación. La narración se ofrece a menudo de forma tan espontánea, que parece que el relato resultante no ha precisado de correcciones. Bob Franklin (2005, p. 96) insiste precisamente en la vaguedad del término y las innumerables interpretaciones de las que ha sido objeto, aunque destaca, al menos, dos elementos diferenciadores: el uso de la primera persona y el protagonismo que adquiere el reportero en el relato como partícipe. El primer aspecto es, o puede ser también, común al periodismo de inmersión, en general, y al periodismo encubierto en concreto. El segundo rasgo, el protagonismo del reportero, es, sin duda, su aspecto diferenciador respecto a otros tipos de periodismo. En su más simple definición, el periodismo gonzo postula al reportero no como un observador inerte 
de los hechos sino como un participante central. Hasta el punto, incluso, de poder alterar a su antojo el curso de los acontecimientos y, cómo no, también sufrir sus consecuencias.

Para Tom Wolfe (1998, p. 54), Hunter S. Thompson es el maestro de esta forma de escritura, aunque asegura que el primer ejemplo que descubrió de esta modalidad de periodismo fue el reportaje de Terry Southern "Bastoneando en Ole Miss" para Esquire. El reportero empieza preparando un artículo de encargo, en concreto un reportaje en el Dixie National Baton Twirling Institute, en Oxford, y acaba escribiendo un reportaje en primera persona, con formato de diario, en el que el reportero describe sus dudas sobre el trabajo, sus presentimientos, cómo llega a la ciudad, sus conversaciones con el taxista que lo lleva al Instituto y otros muchos detalles vinculados a su experiencia personal más que al Dixie National Baton Twirling Institute. Más allá del testimonio de Wolfe, esta modalidad de periodismo tuvo, desde luego, otros pioneros. Ya lo hizo Nellie Bly en La vuelta al mundo en 72 días y, sobre todo, George Orwell en su magnífica obra Sin blanca en París y Londres.

Hunter S. Thompson (Estados Unidos, 1937-2005) acuñó el término gonzo con su crónica "El derby de Kencky es decadente y depravado", pero fue con Miedo y asco en Las Vegas donde alcanza su madurez. Sobre esta obra escribe: "Más o menos... y esta matización es la esencia de lo que, sin ninguna razón determinada, he decidido llamar Periodismo Gonzo. Es un estilo de 'información' basado en la idea de William Faulkner de que la mejor ficción es mucho más verdad que cualquier tipo de periodismo... cosa que saben de siempre los buenos periodistas". Y argumenta después: "Lo que no quiere decir que la ficción sea necesariamente 'más verdad' que el periodismo - o viceversa- sino que tanto 'ficción' como 'periodismo' son categorías artificiales; y que ambas formas, en el mejor de los casos, son sólo dos medios distintos de lograr el mismo propósito" (Thompson, 2012, p. 58).

Reconoce a este respecto que Miedo y asco en Las Vegas es "un experimento fallido de Periodismo Gonzo". Y lo explica: “El verdadero Periodismo Gonzo exige el talento de un gran periodista, el ojo de un fotógrafo/artista y el valor suficiente para participar en la acción. Porque el escritor debe participar en los hechos, mientras los describe, o grabar al menos, 0, como mínimo, tomar notas. 0 las tres cosas. La analogía más próxima al ideal probablemente sea el productor/director de cine que se escribe sus guiones, hace el trabajo de cámara y se las arregla como sea para filmarse en acción, como protagonista 0 , al menos, como uno de los personajes principales" (Thompson, 2012, p. 59). Pero fue Los Ángeles del Infierno la obra que lo encumbró como un narrador excepcional. A Thompson le gustaba vivir al límite. Adicto al alcohol y a las drogas, era arrogante, excéntrico, irritable, le gustaban las armas y ser el centro de atención en todas sus crónicas. 
A comienzos de octubre de 2009, Gabriela Wiener declaraba en un chat con sus lectores que no había tenido presente a la hora de hacer periodismo la figura de Hunter S. Thompson salvo en lo que a "robar cámara se refiere". De hecho, la periodista peruana es contundente cuando ataca y desprestigia la figura del periodista norteamericano, de quien dice que salvo el libro sobre la convención de los moteros, Los Ángeles del linfierno, y un puñado de brillantes reportajes, y por haber sido despedido del Time por insubordinación, "no hizo mucho más por el término que inspiró, como no sea destaparse los sesos. No creó, menos mal, ninguna escuela. Y aún ahora los profes, conscientes del daño que podrían hacerles a la sociedad, enseñan el Periodismo Gonzo del viejo Hunter en la universidad con risitas y desconfianza" (Wiener, 2011c).

\section{La presencialidad de Gabriela Wiener en sus textos}

Los tres libros de Gabriela Wiener, Sexografías, Nueve lunas y Llamada perdida, comparten una característica común: la presencialidad de su autora en los textos. De hecho, como señala María Angulo Egea, es ese ethos exhibicionista, irónico y sincero el que subyuga al lector, que "se siente fuertemente atraído, como un voyeur, por la personalidad desinhibida de esta mujer". Según Angulo, Wiener emplea su sexualidad como arma combativa para remover conciencias. Sexografías ha sido estructurado como un viaje de exploración interna y externa. Externa, referida a la labor reporteril de la periodista, y que le permite obtener datos y declaraciones de los personajes. E interna, porque indaga en su propio yo. La metáfora del cuerpo da unidad y sentido a la obra (Angulo Egea, 2009, p. 13).

El libro recoge una de sus crónicas más controvertidas, y sin duda la mejor de su obra periodística, "El planeta de los swingers", que también Darío Jaramillo recopila, con algunas modificaciones, en su Antología de crónica latinoamericana actual, con el título "Dame el tuyo, toma el mío (Aventuras en un club de intercambio de parejas)". El comienzo, que Wiener siempre cuida, es magistral: "Esta noche me dispongo a ser infiel con permiso de mi marido". Más adelante, confiesa que le intriga "esta aventura conjunta, esta libertad sexual que surge del consenso, este adulterio vigilado". Las confesiones van más allá aún: "Con cinco años juntos, J y yo contamos entre nuestras experiencias liberales con un intercambio frustrado y varios tríos, aunque siempre con una tercera mujer. En cuanto a los celos, tema superado para los swingers, para mí siempre han tenido que ver con el amor o con la fascinación. Si él se enamora de otra o se fascina por alguien, me pongo celosa. Los celos para él pasan por el sexo: si otro hombre me toca, le rompe la cara" (Wiener, $2011^{\text {a }}$, p. 455). 
Su pudor se muestra en las propias vacilaciones que describe. Primera vacilación: quitarse la ropa en medio de un pasillo iluminado, junto a dos adultos mayores "mofletudos y en pelotas". Segunda vacilación: tener sexo delante de tanta gente. Más adelante añade: "Sigo yendo de mano en mano, descubro que me gusta sentirme así, que nadie sepa quién soy, abandonarme a los caprichos de algo que está más allá de mi conciencia" (Wiener, $2011^{a}$, p. 459). Estas sensaciones personales las mezcla con las sensaciones de quienes comparten su experiencia: "He hablado con más de media docena de parejas swingers esta noche y todas defienden su opción como un antídoto contra el virus de la infidelidad. Juran que es una novísima forma de sexualidad, capaz de salvar matrimonios agónicos o al menos de estirarlos" (Wiener, 2011 a , p. 459).

Pero en el texto, más allá de sus confesiones personales, también cabe la descripción y la crítica a estos intercambios de parejas: "Pero lo que ocurre dentro de un club de swingers no se parece tanto a esas escenas de glamour y lujuria que la gente suele imaginar desde afuera. Para empezar, está lleno de panzones sudorosos y mujeres con siliconas” (Wiener, $2011^{\text {a }, ~ p . ~ 60) . ~ E n ~ o t r o ~ m o m e n t o, ~ p r e g u n t a ~ a l ~ m a r i d o: ~ “ ¿ R i c o ~ v e r m e ~ c o n ~}$ otro?" El marido responde: "No, francamente espantoso. Mejor si puedo evitarlo el resto de mi vida". Después añade para el lector: "Yo le diré lo de siempre: verlo con otra me excita tanto como me duele. Hacemos el amor". Tercera vacilación de la noche: hacerlo con la primera pareja poco atractiva que les dirige la palabra (Wiener, $2011^{\text {a }}$, p. 461).

El ritmo del relato va in crescendo. De nuevo, las críticas al mundo de los swingers: la igualdad de oportunidades. Wiener escribe: "Aquí, como en el mundo real, sólo tienen éxito los que son hermosos y sensuales, los que van al gimnasio y se operan. Los que no, tienen que resignarse al onanismo. La competencia puede ser descarnadamente desleal" (Ibídem, $2011^{\text {a }}$, p. 462). En fin, es una crónica sin desperdicio, que atrapa al lector desde las primeras líneas y le hace vivir el mundo de los swingers a través del pudor desinhibido y las experiencias personales confesadas por la autora. Las últimas líneas, en cualquier caso, dejan clara su postura al respecto: "Sé que fui liberal alguna vez, pero sólo hasta que regresé del planeta de los swingers. He traicionado el voto de confidencialidad de la mafia. La última regla para un swinger es no revelar nunca lo que ocurre entre liberales del sexo. Quizá nunca lo fui” (Ibídem, 2011ª , p. 463).

Tal fue el eco de esta crónica, que Gabriela Wiener se prestó a explicar en otro texto, titulado “Swingers, el detrás de la escena”, la razón que la motivó y el método que utilizó para elaborar este relato. Esta metacrónica o metaensayo apareció por primera vez en la edición on line de Etiqueta Negra en 2004. La crónica a la que hacía referencia fue publicada en el número 14 de julio de ese mismo año en la edición impresa de 
la misma revista. En este artículo meta-periodístico, la autora nos revela los recursos literarios empleados, cuenta cómo nos va a contar el relato, sus escenas, su guión, sus descripciones y sus personajes, desvela la estructura interna del texto, da cuenta de su nerviosismo, pero la narradora decide hacer la descripción del escenario tal y como lo vio después (Angulo Egea, 2009, p. 14). Cita, al analizar su crónica, un listado de todo aquello que no quería que fuera: no quería hacer un panegírico; no quería caer en el pintoresquismo; tampoco quería contar la historia de una tribu urbana; no podía ser aburrida pero tampoco masturbatoria. Pero sí quería que fuera un testimonio descarnado de su visita a Swingerlandia al lado de su esposo, pues irían como pareja, no como "periodistas fisgones"; una guía rigurosa de todo lo que se puede encontrar en un club de parejas liberales; una crónica-ensayo que estuviera impregnada de reflexiones y citas, pero que no tuviera pelos en la lengua cuando se tratara de cuestionar su esnobismo, su artificialidad o su mercadeo (Wiener, 2011b, p. 465).

Pero la crónica se inicia realmente cuando ella se está vistiendo y maquillando. Medir la sensación de estar junto a su pareja y arreglarse para ligar con otro, estar desnudos e insinuarse a gente desconocida, vestirse delante de todos, tocar y dejarse tocar por otros. Para Wiener, esta manera de hacer periodismo no tiene una sola justificación. Ésta es la suya: "En ese momento y en el lugar de los hechos, sé que la única forma de ser fiel al espíritu y realidad de esta historia o de cualquier historia es dejarme llevar por el azar, fluir con las situaciones y las personas, de una manera que no podría si lo hiciera presentándome como periodista. Por eso era tan importante que al exhibir la vida y experiencia de los swingers, exhibiera también mi propia intimidad. Que se viera mi desnudez, mi ridículo, mis miedos y mis complejos, mis celos, pero también mi curiosidad, mis fantasías y mi morbo. Digamos que es el costo de ser testigo y parte, si iba a entrometerme tenía que hacerlo hasta el final, y cada cosa que dijera de los swingers también sería algo que podría decir de mí misma". Y añade: "Alguien podría decir que esta crónica trata más de mí que de los swingers. Y no estaría equivocado" (Wiener, 2011b, pp. 467-468).

Gabriela Wiener confiesa que tampoco pretendía escribir sólo un texto desinhibido "para calentar al lector", sino que quería "dar una verdadera tesis sobre los swingers". Quiso esconderse detrás de un montón de citas y sentencias que finalmente rechazó y descartó incluir entrevistas, de modo que lo que quedó fue la historia personal. También discutió mucho con sus jefes sobre el arranque hasta que al final se centró en la pareja. De hecho, el marido fue el contrapunto, ambiguo ante el tema, un recurso que explotó al máximo, y que fue evolucionando de la oposición a la implicación. La periodista peruana, satisfecha con el resultado final, concluye con ironía: "Cuando se publicó la 
historia, muchos colegas periodistas me preguntaron si no me lo había inventado todo. A fecha de hoy mi madre sigue pensando que escribí una ficción. Mejor no desengañarlos" (Wiener, 2011b, pp. 468-469).

Hay que ser una persona especial para escribir Sexografías, sostiene Javier Calvo. Y Gabriela Wiener lo es, añade. La define como un personaje menudo, de "aspecto huraño, ceño enorme y voz apagada, su pose pública consiste en una mezcla estudiada de infantilismo coqueto y provocación impúdica". El tratamiento literario y el enfoque de sus crónicas debe mucho a la revista Etiqueta Negra, en su “interés juguetón por las formas de vida más extremas o grotescas de América Latina, principalmente, ya la mirada distanciada y a menudo sutilmente socarrona sobre sus sujetos" (Calvo, 2011, pp. 9-10).

Pero a Calvo le interesa, sobre todo, la periodista peruana cuando se aleja de ese estilo de escuela. Primero, cuando el tratamiento del yo se expone públicamente a altos niveles de intimidad. En segundo lugar, en la relectura que hace del periodismo gonzo, que va más allá del subjetivismo y cuya implicación adopta "rasgos del gonzo pornográfico: la transmisión de lo impúdico, por ejemplo, o el propio cuerpo como vehículo para la excitación ajena". La tercera parte del libro, titulada “Mi cuerpo", es la preferida de los lectores. En sus páginas, escribe Calvo, "el desnudamiento del yo que alcanza alterna entre lo cándido, lo simpático y lo entrañablemente cochino" (Calvo, 2011, p. 10-11).

Aun así, la última crónica incluida en Sexografías es, en realidad, uno de los capítulos de su segundo libro, Nueve lunas, el testimonio de una embarazada y equívoca madre de estos tiempos, que para Wiener es de lejos "la experiencia más gonzo que he vivido hasta la fecha" (Wiener, 2011b, p. 214).

\section{De Nueve lunas a Llamada perdida}

El libro Nueve lunas, publicado en 2009, no abandona el tono intimista, sincero y desgarrado del anterior. Tal vez, más sincero incluso, más personal. De nuevo el "yo", la primera persona, contando desde adentro un mundo que también es el mundo del lector. En esta crónica-ensayo tan personal, Wiener narra su embarazo. El mes que cumple 30 años, la autora, una escritora peruana y "periodista kamikaze", que se gana la vida en España publicando artículos sobre sexo, está en un hospital recuperándose de una intervención quirúrgica, cuando se entera de que a su padre le han detectado un cáncer de colon, que una amiga acaba de suicidarse y que la revista para la que trabaja ha cerrado. Nueve lunas es una exploración narrativa de los mitos de la procreación. Como se lee en 
la contracubierta del libro, "una guía secreta para las que quieren ser madres a toda costa y las que detestan la idea de serlo, pero también para el voyeur, el donante de semen, el sátiro y el aspirante a padre con babero". Son nueve escenas de un reality obstinado en "amargar la dulce espera con arranques parricidas, delirios biotecnológicos y partos sin anestesia, narradas desde la desconcertante y lúbrica subjetividad de una embarazada que teoriza sobre nuestra neurótica necesidad de perpetuar la especie".

El arranque del libro, siempre certero en todos sus textos, ofrece ya el tono con el que impregnará todas sus páginas: ironía, sinceridad, sentimiento, desgarro. Dice así: "En estos últimos meses, nueve, para ser exactos, he llegado a pensar que el placer y el dolor siempre tienen que ver con cosas que entran o salen de tu cuerpo" (Wiener, 2009, p. 11). El libro también lo cierra la autora de manera magistral. En el último capítulo, previo al epílogo, narra el momento cuando le entregan a la hija. Tampoco ella puede evitar el sentimentalismo y la lágrima. Complicado en ella, pero lo consigue. Y escribe: "Creo que va a embargarme el sentimentalismo y quiero evitarlo a toda costa, como siempre. Y, como siempre, fracasaré. Ahora sí viene, se abre paso, la siento llegar, la veo, alzada por los aires, embarrada de mis entrañas, tibia, decolorada, con rostro de boxeadora, me la enseñan como un camarero te enseña una botella de vino, como si pudiera decir que no la quiero, la tienden sobre mí, ya no es una extensión de mí misma, es otra. ¿Lloraré? Si me pregunto esto es que lloraré" (Wiener, 2009, p. 152).

Esta crónica-ensayo está escrita con una prosa pulcra, tal vez más cuidada en crónicas anteriores, un texto que ofrece múltiples giros y una mirada diferente sobre el mundo del embarazo. Un periodismo gonzo que, obviamente, no le está permitido escudriñar a cualquier periodista. Los detalles minuciosos sobre su propia vida los entremezcla la autora con las vivencias propias del embarazo, los cuidados médicos, las dudas y las esperanzas que la embargan. Pero también otros embarazos frustrados. El primero, cuandolos padres la llevan a abortar a un edificio siniestro en el barrio de María Jesús. El médico era de alguna ONG y amigo de los padres. Estaba despierta. Le dijo al médico que no podía hacerlo. La enfermera la abraza. La succión le produjo un enorme dolor y gritó. El médico solamente dijo: "No grites, que el aborto es ilegal en este país y los vecinos pueden quejarse de los gritos". Después escribe Wiener: "Sorbí mis lágrimas en silencio, aguantando la pena, aguantando el asco y la sensación de que si bien no era como una violación, seguro se parecía mucho" (Wiener, 2009, p. 40).

La segunda vez que quedó embarazada, la llevó a abortar el chico que era el presunto padre, el chico que le hizo olvidar no sólo el primer amor, sino lo que era el amor, confiesa. Es desgarrador cuando narra ese momento: "Supongo que nadie va a esos 
sitios por las buenas, creo. Días antes me había roto la nariz de un puñetazo. Yo lo había sometido a largas sesiones de violencia psicológica e infidelidades sistemáticas que, en mi comovisión, eran maneras de vengar su incapacidad para hacerme el amor después de la guerra. Me odiaba y lo odiaba a él, para qué íbamos a tener un hijo. Que el resto de nosotros también se fuera por las cañerías. Fue una excelente iniciativa de su parte que aplaudí sólo mucho después" (Wiener, 2009, p. 41).

En Nueve lunas tuvo un olvido que recupera en su siguiente libro. En aquél no contó la historia de aquellos días de infausta dictadura en Perú en que la madre estaba embarazada de ella y su papá estaba encerrado en la cárcel por izquierdista. Y escribe en Llamada perdida: "Qué raro que no lo contara en Nueve lunas (mi libro sobre mi embarazo), ¿no, mamá?, le pregunté realmente fastidiada. 'Sí, hija, tú que lo cuentas todo... Con tu hermana en la barriga yo corría de la policía en pleno paro nacional. Y contigo iba al venusterio.' En ese momento creí entender muchas cosas" (Wiener, 2015, p. 103).

Con el mismo desgarro está escrito su tercer libro de crónicas. En éste cambió de registro a la hora de seleccionar el género, de manera que el volumen lo conforman crónicas personales, entrevistas-perfil, artículos, breves ensayos, un diálogo con ella misma o autoentrevista, como también lo hicieran antes Truman Capote u Oriana Fallaci, en este caso vía telefónica, atendiendo al título del libro. En este sentido, también Llamada perdida es crónica, ensayo y autobiografía o memorias. Un libro sincero e irónico donde habla de tríos sexuales, de sus experiencias con la muerte, de los límites del pudor; eso sí, sin pudor alguno. Tal vez en los textos que integran este volumen el periodismo gonzo de Wiener haya ido más lejos que en otros en su sinceridad, en el desgarro con que muestra su intimidad. Muchos escritores y periodistas han fabricado su propio autorretrato. Desde Cervantes a Pablo Neruda o Gabriel García Márquez. Pocas veces, como en éste de Gabriela Wiener, sinceridad, intimidad, ironía, impudor combinan en un cóctel perfecto. En efecto, el libro incluye también otro género: el autorretrato. De una prosa limpia y precisa, sin duda está a la altura de los mejores autorretratos hasta ahora escritos: "Nadie podrá despreciarme mejor que yo. Ésa es mi conquista. La voz interior es siempre un recuento de catástrofes y barroquismos: mis dientes torcidos, mis rodillas negras, mis brazos gordos, mis pechos caídos, mis ojos pequeños clavados en dos bolsas de ojeras negras, mi nariz brillante y granujienta, mis pelos negros de bruja, mis gafas, mi incipiente joroba y mi incipiente papada, mis cicatrices, mis axilas peludas y abultadas, mi piel manchada, picosa y lunareja, mis pequeñas manos negras con las uñas carcomidas, mi falta de cintura y curvas traseras, mi culo plano, mis cinco kilos de sobrepeso, los pelos hirsutos de mi pubis, el pelo de mi ano, los pezones grandes y marrones, mi abdomen descolgado y estriado. El tono 
de mi voz, mi aliento, el olor de mi vagina, mi sangre, mi fetidez. Y aún me falta hacerme vieja. Y descomponerme" (Wiener, 2015, pp. 11-12). A ella, por supuesto, le gusta añadir: "Soy una periodista especializada en meterse en sitios y escribir en primera persona sobre experiencias extremas" (Wiener, 2015, p. 46).

Ya advierte la periodista peruana en las primeras páginas de su libro que se ha ido de putas en París, que ha hecho cosas raras que para algunos podrían ser audaces, que ha tenido experiencias pero que, de un tiempo a esta parte, le atraen otro tipo de aventuras, le atrae el relato del tejido social y emocional en el que vive. Reconoce que nunca ha podido hacerse invisible pero sí que en ocasiones ha podido narrar desde un lugar discreto. Ama la voluntad de asombro. De niña se intoxicó con la lectura de poetas confesionales, con los artistas que escribían con su sangre, con los documentales que hacen los hijos sobre sus familias y con libros de memorias, "narraciones llenas de episodios bochornosos". Y todas estas experiencias la llevaron a que la materia de estudio de Gabriela Wiener fuera la propia Gabriela Wiener. Y añade: “La intimidad es mi materia y es mi método. Y, sí, esa necesidad de exponerme tiene que ver más con la inseguridad que con la valentía. La autorrepresión siempre me pone al borde del arrebato y en situaciones incómodas de las que nunca sé cómo salir. Pero salgo y salgo un poco distinta" (Wiener, 2015, p. 8).

Como Gay Talese, forma parte de ese grupo de escritores que son excavadores que buscan en lo real lo impredecible y lo extraño, aunque también lo abrumador, de la normalidad, el absurdo que contienen las noticias, confiesa, "todo eso que puede ser tan serenamente triste como una llamada perdida". Ella se justifica así: "Creo que lo más honesto que puedo hacer es contar las cosas como las veo, sin artificios, sin filtros, sin mentiras, con mis prejuicios, obsesiones y complejos, con las verdades en minúscula y por lo general sospechosas. Hacerlo de otra manera sería presuntuoso por mi parte. Estaría engañándome y engañándolos" (Wiener, 2015, p. 8).

En Llamada perdida también forma parte del taller Vive tu muerte, entrevista a Corín Tellado e Isabel Allende, muestra su afición por la fotografía y por coleccionar fotos (13.407 sólo de los últimos siete años), habla con ella misma por teléfono y se pregunta qué sintió el otro día que la insultaron en un periódico, a lo que su otro "yo" le responde: "Es el precio de ser sincera" (Wiener, 2015, p. 122). También habla de su madre y escribe que le preguntan si le da miedo que ella lea las cosas que ha publicado, que ha "confesado". Y añade: "Nunca he confesado nada. Hay algo perverso en la palabra confesión. Dentro habita la palabra 'culpa'. Yo suelo contestarles que no tengo miedo porque sé que mi hija conoce el (verdadero) valor de la verdad" (Wiener, 2015, p. 101). En el mismo texto curiosamente titulado "Acerca de lo madre". Se entiende el título cuando 
se lee el siguiente párrafo en el que narra el sabor que le dejó para siempre la lectura de Los perros románticos de Roberto Bolaño y donde una vez más se muestra solidaria con quienes se sienten solos o marginados en el mundo que describe: "Todos los que alguna vez se han sentido marginales deberían leerlo. Reconocerse es una aventura fabulosa. Los desheredados de siempre, los homosexuales, a quienes alguna vez llamaron feos, los adictos al sexo, los guapos tímidos, los eyaculadores precoces, las gordas, los enfermos, las lesbianas, los muertos, quienes tienen la boca llena de palabras hermosas y salvajes y por eso no van a callarse" (Wiener, 2015, p. 99).

De nuevo, con el mismo desgarro y la misma sinceridad vuelve sobre temas tratados en los otros libros: sexo, tríos, fidelidad, pareja. Valga como botón de muestra este último párrafo que da coherencia a toda una obra periodística que siempre gira sobre el mismo eje, que es la intimidad de su autora, con sus dudas y sus deudas, con sus convicciones y sus extravíos, con su juego de palabras y su prosa precisa, que viene a ser el segundo tramo de su autorretrato: "He sido infiel a todos, una noche y muchos años. Lo he sido en una escalera, en varios autobuses, en decenas de hoteles sin estrellas y bajo un cielo estrellado. En una playa, en un parquin, en un museo, en un abismo, en sus narices. He sido infiel un Viernes Santo, un Día de la Madre, una Navidad y hasta durante un golpe de Estado. Borracha, sobria, recién levantada y a punto de dormirme. Les fui infiel con mis vecinos, con mis compañeros de estudio, con mis colegas del trabajo, con mis exnovios, con mis amigos, con mis amigas, con sus mejores amigos, con sus otros yos, con extraños fascinantes y con simples extraños. Con seis el mismo día, con dos la misma noche, con tres en la misma cama. Fui infiel sobre todo a mis infidelidades. Y, por supuesto, me casé con una de ellas" (Wiener, 2015, p. 67).

\section{Dicen de mí: un libro en el que los otros hablan de Gabriela Wiener}

En su último libro, Dicen de mí, Wiener da una vuelta de tuerca. Como dice su autora, no se trata de un libro sobre "su yo". Ella no habla de ella. Muy al contrario, hablan de ella a través de entrevistas 16 personas muy cercanas a la autora que responden a aquellas preguntas que nunca se atrevió a hacer: su marido, su madre y su padre, su hermana, su antigua psicóloga, su hija Lena, su primer jefe, la madre de su hijo, escritores como Leila Guerriero o Jorge Carrión, entre otros. El libro es un juego de espejos en el que ella se muestra a través de las palabras de quienes han significado o significan algo en 
su vida. En definitiva, entrevistas que tratan sobre la propia entrevistadora. Una especie de metaperiodismo, como lo define ella misma, que le ayuda, con la voz de los otros, a completar ese retrato propio que fue construyendo en libros anteriores. Un libro diferente, eso sí, un libro experimental, en el que la autora sigue siendo el tema a tratar. Aunque esta vez, ella perfila a los entrevistados y los entrevistados, empujados por sus preguntas, hablan de ella. Y no siempre, como es obvio, positivamente.

En la primera entrevista recopilada en el libro, pregunta a Jaime, el marido, cómo es ella. Él responde: "No eres la mejor persona que conozco, pero sí la más interesante. Eres sumamente egoísta, estás anclada de alguna manera a una parte de tu infancia que es a la vez estridente y oscura. Por otro lado, eres tan perspicaz, tan necesariamente cruel con ciertas cosas, que produces inteligencia. Eres brillante y aún ahora, después de todos estos años, sigues siendo como una fiesta sorpresa. Aunque siempre te comas la torta. No podría vivir sin ti” (Wiener, 2018, p. 18). A su hermana Elisa le pregunta que qué le parece que la entreviste para hablar de ella misma. Elisa responde: "Es tu tema favorito y supongo que soy una de las personas que mejor te conoce, digamos desde el origen. Quizá esta entrevista vaya de eso. Llevo una vida hablando de ti”. Y más adelante, añade: “Aún hoy a veces te es difícil ver a la buena que hay en ti” (Wiener, 2018, pp. 22-23). Elisabeth Crosby fue su psicoterapeuta. Y dice de Wiener qué sacó afuera de ella: "Que había un tema con el color de tu piel que te atormentaba. Que eras alguien que daba mucha importancia a lo sexual... Hay una parte tuya despectiva, soberbia, competitiva, envidiosa, narcisa que te impide conocer a los demás, que te impide conocer cualquier otra cosa más allá de ti misma" (Wiener, 2018, p. 35).

Algunos de los entrevistados prefieren hablar de su obra más que de su vida. Jorge Carrión critica con firmeza estos libros suyos que la autora califica como "mis libros de cajón de sastre". Carrión es tajante: “Lo que tendrías que hacer es dejarte de entrevistas como esta, para libros como este, y escribir el libro sobre tus raíces alemanas y la exploración de Machu Picchu que estás pensando hace tiempo. Lo que los lectores necesitamos de ti no son más artículos y experimentos, sino un gran libro, una gran novela, de ficción o sin ella" (Wiener, 2018, p. 112). En otro momento, lanza el dardo sobre su persona. La compara con Carol Rama y le dice: "Creo que te pareces a ella. Que has optado por protagonizar una vida interesante, distinta, original, radical, muy artística. Que se escribirán biografías sobre ti, que serás objeto de estudio. Que tu gran novela es tu propia vida. Pero como Jaime es un personaje también muy importante en ella, creo que él se merece que en el futuro tú te sacrifiques por él como él ha estado haciendo por ti, y que volváis a Barcelona" (Wiener, 2018, p. 115). La periodista argentina Leila 
Guerriero también es crítica con su obra y le aconseja que experimente por otras vías que no conduzcan siempre al yo ni desemboquen en la autobiografía: "Lo que me pasa con tu trabajo, Gabi, es que es muy único, no solo tienes una voz muy única, sino también una intención muy única. Si yo tuviera que decirte algo, en cuanto a tu trabajo, tal y como lo estás haciendo, quizá podría decirte algo que me digo a mí misma muy a menudo: tratá de ponerte incómoda, recorrer otros senderos. Creo que siempre conviene trabajar un poco en contra de los caminos que una ya conoce. Hacete una crónica tradicional..." (Wiener, 2018, p. 102). Pese a lo arriesgado del tono personal de cualquier texto de Wiener, no deja de llamar la atención cómo Carrión y Guerriero le aconsejan que abandone esta línea tan personal para indagar en otros territorios desconocidos.

El libro contiene asimismo dos testimonios sumamente interesantes de analizar. Uno es el de su ex mejor amiga, Celia Leal. Mantuvo un trío con ella y Jaime, su marido. Wiener escribe: "No importa cuántos seamos en la cama, una triste historia de amor siempre es una triste historia de amor. Y esta lo fue. También es la historia de cómo se construye a veces el deseo y su ruina" (Wiener, 2018, p. 60). Leal cierra la entrevista con esta frase: "Piensa si realmente sentías que era tu amiga y me respetabas, o se convirtió en tu hobby sacar fortaleza de la debilidad de otros. Cuando llegues al nivel de humildad de reconocer eso, o al menos de tomarlo en cuenta, podemos aproximarnos; de lo contrario, quédate con la idea de que te deseo absolutamente lo mejor, que no te odio ni te odiaré, pero que prefiero la distancia" (Wiener, 2018, p. 64). El libro se cierra con una entrevista imposible, una entrevista a una expareja, cuyo nombre se mantiene en el anonimato, y que en su día le partió la nariz. Veinte años después de aquella relación, la expareja sigue entrecomillando la palabra "puñetazo". No es sino hasta este texto que la periodista peruana cuenta que sufrió violencia machista, y que fue consciente de que no estaba luchando contra una persona, sino contra todo un sistema. Este último texto no es ya una entrevista, frente a la negativa de él, sino una reflexión lúcida sobre el machismo. Cierra esta reflexión y el libro con esta frase: "Casi veinte años después, la persona que fue mi pareja pone entre comillas la palabra 'puñetazo'. Y yo las quito. Y al quitarlas el puñetazo duele menos" (Wiener, 2018, p. 155).

\section{Conclusiones y discusión}

El periodismo de Gabriela Wiener hay que enmarcarlo dentro de la corriente de periodismo narrativo que ha innovado el género en las dos últimas décadas en el 
continente americano. Ha ejercido el periodismo de inmersión y el periodismo encubierto pero, además, es la principal precursora del periodismo gonzo en español. 0 periodismo kamikaze, como a ella le gusta denominarlo. Pese a haber innovado esta modalidad de crónica personal, mantiene notables diferencias con su creador, Hunter S. Thompson, en tanto que la peruana se muestra en sus textos más sincera y nada pudorosa, desgarrada e irónica.

Su prosa es limpia y clara. Cuida los arranques y los cierres en cada uno de los géneros que cultiva. Es autora, sobre todo, de la crónica personal e intimista, pero trabaja la crónica-ensayo y se ha abierto cada vez más a otros géneros como el artículo y el ensayo breve, la entrevista-perfil, el artículo y la autoentrevista, así como textos híbridos que fusionan crónica, ensayo, memorias y autobiografía, incluso el cómic periodístico. Y recurre también a la metacrónica, un recurso que, como señala María Angulo Egea, refleja la transparencia en el ámbito profesional: "Este making of de la crónica que consiste en hablar del proceso de elaboración y cómo se siente el yo del periodista ante los hechos que van sucediendo. La visión de la periodista se plasma en el proceso de obtención de información, en su paulatina inmersión o en cómo se ha enfrentado a las diferentes situaciones" (Angulo Egea, 2017, p. 148).

En su último libro, Dicen de mí, busca nuevos recursos narrativos para hablar de "su yo" a través de entrevistas un tanto pecualiares. Ella no habla de ella. Muy al contrario, hablan de ella a través de entrevistas personas muy cercanas a la autora que responden a aquellas preguntas que ella nunca se atrevió a hacer. No deja de ser un libro experimental, que le desaconsejan Jorge Carrión y Leila Guerriero, pero que insiste en este metaperiodismo que una vez más se adentra en el "yo" de la periodista peruana.

Los temas nunca escapan a su cuerpo ni a su biografía, a sus deseos y a sus fobias: sexo, embarazo, aborto, tríos, violencia, feminismo, machismo. Sus textos son sinceros e intimistas, testimoniales, pero nunca confesionales, porque la autora rechaza el concepto de culpa. Gabriela Wiener es la materia de estudio de Gabriela Wiener. Y también su método. Describiéndose también describe el mundo. Un periodismo tan personal nadie lo escribió en español como ella. 0 como ella lo dice: "Gonzo soy yo". Pero es una periodista gonzo diferente, con un sello muy sui generis. No obstante, la vuelta a la crónica tradicional por parte de la periodista peruana ayudaría a ubicar con más precisión una obra tan singular y a entender con más conocimiento la obra que mañana comenzará a escribir. 


\section{Bibliografía}

Agudelo, D., (Ed) (2011). Antología de crónica latinoamericana actual. Madrid: Alfaguara.

Angulo Egea, M. (2009): Las mujeres en el periodismo literario: tres casos paradgimáticos, en Actas del I Congreso Internacional Latina de Comunicación Social, Tenerife: Universidad de La Laguna. Recuperado de http://www. revistalatinacs.org/09/Sociedad/actas/89angulo.pdf

Angulo Egea, M. (2017): Inmersiones. Crónica de viajes y periodismo encubierto. Barcelona: Universidad de Barcelona.

Calvo, J. (2008): Una vida de impudicia, en Wiener, Gabriela (2008): Sexografías. Barcelona: Editorial Melusina, 9-11.

Dader, J. L. (2007). Del periodismo pasible, la obviedad informativa y otras confusiones en el Estanco de Noticias, en Estudios sobre el mensaje periodístico (13), 31-53.

De Miguel, R. (2005). La observación sistematica y participante como herramienta de análisis de los fenómenos comunicativos, en Berganza Conde, M. R. y Ruiz San Román, J. A. (Eds.): Investigar en Comunicación. Guía práctica de métodos y técnicas de investigación social en Comunicación. Madrid: McGraw Hill, 251-263.

Franklin, Bob et al. (2005): Key Concepts of Journalism Studies. London: SAGE Publications.

López Hidalgo, A. y Fernández Barbero, M. A. (2013): Periodismo de inmersión para desenmascarar la realidad. Salamanca: Comunicación Social.

López Hidalgo, A. (coord.) (2018): Periodismo narrativo en América Latina. Salamanca: Comunicación Social.

López Noguero, F. (2002): El análisis de contenido como método de investigación, en Revista de Educación, (4), 167-179.0, Fernando (2002): ...s de esta modalidad periodiener en el ejercicio del periodismo de inmersito. Su $\mathrm{m}$

Thompson, Hunter S. (2012): La gran caza del tiburón. Barcelona: Debate. 
Wiener, G. (2008): Sexografías. Barcelona: Editorial Melusina.

--- (2009): Nueve lunas. Barcelona: Editorial Mondadori.

---- (2011a): Dame el tuyo, toma el mío (Aventuras en un club de intercambio de parejas), en Jaramillo Agudelo, D., (Ed): Antología de crónica latinoamericana actual. Madrid: Alfaguara, 453-463.

---- (2011b): Swingers, el detrás de la escena, en Jaramillo Agudelo, D., (Ed.): Antología de crónica latinoamericana actual. Madrid: Alfaguara, 464-469.

---- (2011c): Gonzo soy yo, en Sigue Leyendo, 27 de enero. Recuperado de http://www.sigueleyendo.es/gonzo-soy-yo/

--- (2015): Llamada perdida. Barcelona: Debate.

---- (2018): Dicen de mí. Madrid: Esto no es Berlín.

Wolfe, Tom (1998): El nuevo periodismo. Barcelona: Anagrama. 